\title{
On discharge from poppet valves: effects of pressure and system dynamics
}

\author{
P. M. Winroth ${ }^{1}$. C. L. Ford ${ }^{1}$ •P. H. Alfredsson ${ }^{1}$
}

Received: 29 September 2017 / Revised: 27 November 2017 / Accepted: 9 December 2017 / Published online: 15 January 2018

(C) The Author(s) 2018. This article is an open access publication

\begin{abstract}
Simplified flow models are commonly used to design and optimize internal combustion engine systems. The exhaust valves and ports are modelled as straight pipe flows with a corresponding discharge coefficient. The discharge coefficient is usually determined from steady-flow experiments at low pressure ratios and at fixed valve lifts. The inherent assumptions are that the flow through the valve is insensitive to the pressure ratio and may be considered as quasi-steady. The present study challenges these two assumptions through experiments at varying pressure ratios and by comparing measurements of the discharge coefficient obtained under steady and dynamic conditions. Steady flow experiments were performed in a flow bench, whereas the dynamic measurements were performed on a pressurized, 21 , fixed volume cylinder with one or two moving valves. In the latter experiments an initial pressure (in the range 300-500 kPa) was established whereafter the valve(s) was opened with a lift profile corresponding to different equivalent engine speeds (in the range $800-1350 \mathrm{rpm}$ ). The experiments were only concerned with the blowdown phase, i.e. the initial part of the exhaustion process since no piston was simulated. The results show that the process is neither pressure-ratio independent nor quasi-steady. A measure of the "steadiness" has been defined, relating the relative change in the open flow area of the valve to the relative change of flow conditions in the cylinder, a measure that indicates if the process can be regarded as quasi-steady or not.
\end{abstract}

\section{Introduction}

An increased awareness of the effects of global warming has motivated efforts to make transportation more fuel efficient. The most common way to improve fuel efficiency in internal combustion engines is through 'downsizing'; wherein a smaller engine (with lower losses and less weight) performs the task of a larger engine. This is typically accomplished by fitting the smaller engine with a turbocharger, to recover some of the energy from the hot exhaust gases. Such engine systems need careful optimization. When optimizing an engine system it is common to use $1 \mathrm{D} / 0 \mathrm{D}$ simulations. This

This paper is based on the work published in the licentiate thesis of the first author Winroth (2017a).

\section{P. H. Alfredsson \\ phal@mech.kth.se \\ P. M. Winroth \\ marwin@mech.kth.se}

1 Competence Center for Gas Exchange (CCGEx), KTH Mechanics, Royal Institute of Technology, SE 10044 Stockholm, Sweden study focuses on exhaust flows, which in such models are treated as a $0 \mathrm{D}$ emptying process using a discharge coefficient $\left(C_{\mathrm{D}}\right)$, defined as:

$C_{\mathrm{D}}=\frac{\dot{m}_{\text {actual }}}{\dot{m}_{\text {ideal }}}$,

where $\dot{m}_{\text {actual }}$ is the actual mass-flow and $\dot{m}_{\text {ideal }}$ is the massflow rate if the flow was isentropic, i.e without losses. For subsonic flows $\dot{m}_{\text {ideal }}$ can be calculated as:

$\dot{m}_{\text {ideal }}=\frac{A_{\mathrm{T}} p_{0}}{\sqrt{R T_{0}}}\left(\frac{p_{\mathrm{T}}}{p_{0}}\right)^{1 / \gamma}\left\{\frac{2 \gamma}{\gamma-1}\left[1-\left(\frac{p_{\mathrm{T}}}{p_{0}}\right)^{\frac{\gamma-1}{\gamma}}\right]\right\}^{\frac{1}{2}}$,

where $A_{\mathrm{T}}$ is the minimum geometrical flow area (commonly called throat area), $T_{0}$ and $p_{0}$ are the total temperature and total pressure respectively (taken as the temperature and pressure in the cylinder in the experiments), $p_{\mathrm{T}}$ is the static pressure at the throat, $\gamma$ is the heat capacity ratio and $R$ is the specific gas constant. If the flow is choked $p_{\mathrm{T}} / p_{0}$ becomes constant

$\frac{p_{\mathrm{T}}}{p_{0}}=\left(\frac{2}{\gamma+1}\right)^{\gamma /(\gamma-1)}$, 
and the expression can be simplified to:

$\dot{m}_{\text {ideal }}=A_{\mathrm{T}} p_{0} \sqrt{\frac{\gamma}{R T_{0}}}\left(\frac{2}{\gamma+1}\right)^{(\gamma+1) /[2(\gamma-1)]}$.

To obtain the discharge coefficient of the exhaust valve, experiments have to be performed and are typically performed at fixed valve lifts, using a low-pressure, steady-flow rig. By measuring $C_{\mathrm{D}}$ at different valve lifts a look-up table is created. This can be used in the 0D simulations to calculate the mass-flow at any given valve lift. The calculated mass-flow is then used as the boundary condition for the 1D simulations of the flow in the exhaust system (for more information on engine simulations see e.g. Heywood 1988). Simulations with $C_{\mathrm{D}}$ determined from such experiments rely on two assumptions about the exhaust process: (1) quasisteadieness and (2) insensitivity to pressure ratio.

Whilst these assumptions seem reasonable, their validity has not been unambiguously confirmed. Previous studies on the subject are relatively few and contradictory in their support or rejection of the assumptions.

The effect of high pressure ratios, using a steady flow bench with pressure ratios up to $p_{0_{\text {cyl }}} / p_{\text {port }} \approx 4.8\left(p_{0_{\text {cyl }}}\right.$ is the cylinder total pressure and $p_{\text {port }}$ is the exhaust port static pressure) was investigated by Woods and Khan (1965). It was found that for low lifts $(\ell / d<0.04, \ell$ is the valve lift and $d$ is the port diameter) the effective area was independent of the pressure ratio. For larger valve lifts $(\ell / d>0.04)$, at pressure ratios $p_{0_{\text {cyl }}} / p_{\text {port }}<2$, the effective area either increased or decreased, depending on the geometry. For $p_{0_{\text {cyl }}} / p_{\text {port }}>2.2$ the effective area was shown to become constant for any given valve lift, partially supporting the assumption of pressure ratio insensitivity.

Decker (2013) investigated the values of $C_{\mathrm{D}}$ of two different geometries under "blowdown-like" conditions. The experimental setup consisted of a pressurised cylinder, which was fitted to a cylinder top, exhausting to the atmosphere. When a pressure ratio $\left(p_{0_{\mathrm{cyl}}} / p_{\mathrm{atm}}\right)$ of approximately nine was reached, the valve was quickly opened to a fixed lift and the cylinder was allowed to discharge (two valve lifts were tested, $\ell / d \approx 0.03$ and 0.06 ). The mass-flow rate was determined from the cylinder pressure (a similar method is used in the present study) and $C_{\mathrm{D}}$ was evaluated from when the valve reached the desired lift, until a given pressure threshold ( $p_{\text {cyl }}=200 \mathrm{kPa}$ ), giving an approximate pressure-ratio range from 2.0 to 7.5 . In that study, $C_{\mathrm{D}}$ was shown to decrease as the cylinder pressure increased. The study also showed that a modified port geometry, which gave a 6-7\% increase in $C_{\mathrm{D}}$ for steady measurements, actually showed a decrease of $1-3 \%$ in $C_{\mathrm{D}}$ when measured during the more realistic "blowdown-like" conditions.
This suggests that neither the quasi-steady nor the pressure ratio insensitivity assumptions are valid.

An alternative approach to using a discharge facility is to use a pulsating flow, as Bohac and Landfahrer (1999) did. They investigated the quasi-steady assumption by comparing the mass flow measured on a pulsating flow bench (with a pulsation frequency equivalent to $6000 \mathrm{rpm}$ ) to the mass flow calculated using $1 \mathrm{D}$-simulations, using $C_{\mathrm{D}}$-values obtained through steady measurements. The measurements were performed at fixed valve lifts, at pressure ratios of approximately 1.06 . For the valve lifts they claim to be most important to the engine performance $(0.12 \leq \ell / d \leq 0.28)$, the mass flow obtained through simulations were within $0.5-2.5 \%$ of the measured values. They assert that the quasisteady assumption is reasonable and can be used for engine simulations.

With the development of computing power it is now also possible to do large eddy simulation (LES) of the exhaust process. Semlitsch et al. (2014) used LES to compare $C_{\mathrm{D}}$ for steady conditions to $C_{\mathrm{D}}$ under pulsating conditions (equivalent to $1500 \mathrm{rpm}$ ). In the simulations a fixed valve lift $(\ell / d \approx 0.12)$ was used. Large differences in the flow-field were found between the steady and pulsating cases and the addition of pulsation resulted in a $2 \%$ decrease in $C_{\mathrm{D}}$ and they recommend measuring $C_{\mathrm{D}}$ under pulsatile conditions.

In another study Semlitsch et al. (2015) investigated how valve and piston motion affects the exhaust process, again using LES. In this study, they performed simulations on a double exhaust-valve cylinder top. Three different types of valve and piston motions were investigated: (i) Moving valves $(0.08 \leq \ell / d \leq 0.36)$ and a moving piston, (ii) initially moving valves which stopped at $\ell / d=0.12$ $(0.08 \leq \ell / d \leq 0.12)$ with the full piston motion and (iii) steady flow with fixed valves. The simulated engine speed was $1200 \mathrm{rpm}$ and the initial pressure ratio $\left(p_{\text {cyl }} / p_{\text {port }}\right.$ at $\ell / d=0.08$ ) was 1.77 . For case study (i) the flowfield at the end of a discharge period (when the valve had returned to $\ell / d=0.08$ ) was used for the initiation of the flow at the start of each cycle. The study showed large differences in flow-field characteristics between the different case studies. However, they claim that the small differences, that could be noted in $C_{\mathrm{D}}$, represent an "error" and that the piston and valve motion can be neglected when performing low order modelling, i.e. implying that the discharge can be considered as quasi-steady.

Benson (1959) compared $C_{\mathrm{D}}$ for a two-stroke engine (where the exhaust port opening is determined from the piston motion) under steady and dynamic conditions. In the dynamic experiments pressurised air was supplied to a mechanically driven engine. The release pressure ratio was approximately $p_{\text {cyl }} / p_{\text {atm }}=4$ and the engine speed varied from 324 to $654 \mathrm{rpm}$. The mass flow out of the cylinder was calculated from the cylinder pressure trace and the release 
temperature of the gas in the cylinder. It was shown that the $C_{\mathrm{D}}$ measured during dynamic conditions was considerably lower than those measured under steady conditions, indicating that the quasi-steady assumption is invalid.

The quasi-steady assumption was also investigated by Woods and Khan (1967), who compared pressure measurements from a dynamically discharging fixed volume cylinder and pressures calculated using $1 \mathrm{D}$ simulations with $C_{\mathrm{D}}$ values obtained through steady flow experiments. The initial pressure ratio was in the range of $1.89 \leq p_{\text {cyl }} / p_{\text {port }} \leq 3.52$ for engine speeds in the range of $407 \leq n \leq 808 \mathrm{rpm}$. They conclude that even though $C_{\mathrm{D}}$ depends on both valve lift and pressure ratio, the pressure ratio can be neglected in the unsteady flow calculations. They reasoned that $C_{\mathrm{D}}$ was independent of pressure ratio at low valve lifts and at higher valve lifts (where $C_{\mathrm{D}}$ is more sensitive) the pressure ratio change is small. By comparing the measured pressures (in the cylinder and a flow restriction located downstream of the port) with the simulated pressures they also concluded that the process could be modelled as quasi-steady.

As the review of the previous studies highlights, there is no clear picture regarding the validity of the quasi-steady assumption or the assumption that $C_{\mathrm{D}}$ is insensitive to pressure ratio. This motivates the present study, wherein these assumptions are directly tested by comparing $C_{\mathrm{D}}$ obtained through steady flow experiments to $C_{\mathrm{D}}$ measured on a discharging cylinder. The present experiments focus on the blowdown phase of the exhaust stroke, i.e. the initial part of the exhaustion where the pressure ratios are high and the limiting flow area is located around the valve head. Because of this the investigated valve lifts are limited to $\ell / d \leq 0.2$ $(\ell \leq 7 \mathrm{~mm})$.

In Sect. 2 the static and dynamic experimental setups, the geometry of the valve and seat as well as the method to determine the time-resolved mass flow rate are described. Section 3 shows the experimental results both for the static and dynamic tests for the one-valve cases, whereas Sect. 4 discusses a suggested new measure of unsteadiness, i.e. when the flow can be considered quasi-steady. In this section, also results from the double-valve experiments are shown indicating that dynamic effects are even stronger here, in agreement with the new measure of unsteadiness. Finally, Sect. 5 summarises the results and gives some conclusions drawn from the work.

\section{Experimental method}

The experiments can be divided into two types: static and dynamic. In the static experiments the valve was mounted in a cylinder setup, with a fixed lift and a steady flow exhausted through the valve using a gas stand (Sect. 2.1) with air at room temperature. The dynamic experiments used a moving valve, through which air, initially at room temperature, was discharged from a pressurised cylinder of similar size as a heavy-duty engine cylinder (Sect. 2.2). The key components (i.e. valve, seat, port and cylinder dimensions) are common to both the static and dynamic rigs. Both the valve and the valve seat are taken from a Scania diesel engine. In Sect. 2.3 the geometry of the valve/seat opening is shown especially with reference to the smallest area, whereas Sect. 2.4 describes the method used to determine the time-resolved mass-flow rate.

Photos of the two test rigs can be seen in Fig. 1.

\subsection{Static-valve rig setup}

The static valve experiments were performed in the CICERO-laboratory, at the Fluid Physics Laboratory at KTH (Laurantzon et al. 2012). Two screw compressors (Ingersoll Rand Nirvana 75 and SSR ML75, C in Fig. 2) supply pressurised dried air to a tank (T), that is kept at a nominal pressure of $530 \mathrm{kPa}$. The compressors are capable of delivering a maximum mass flow of $0.5 \mathrm{~kg} / \mathrm{s}$ at a pressure of $500 \mathrm{kPa}$ into the laboratory, which is delivered through a $30 \mathrm{~m}$ long pipeline system (pipe diameter $100 \mathrm{~mm}$ ). Before entering the laboratory, the piping is split into a main branch (going

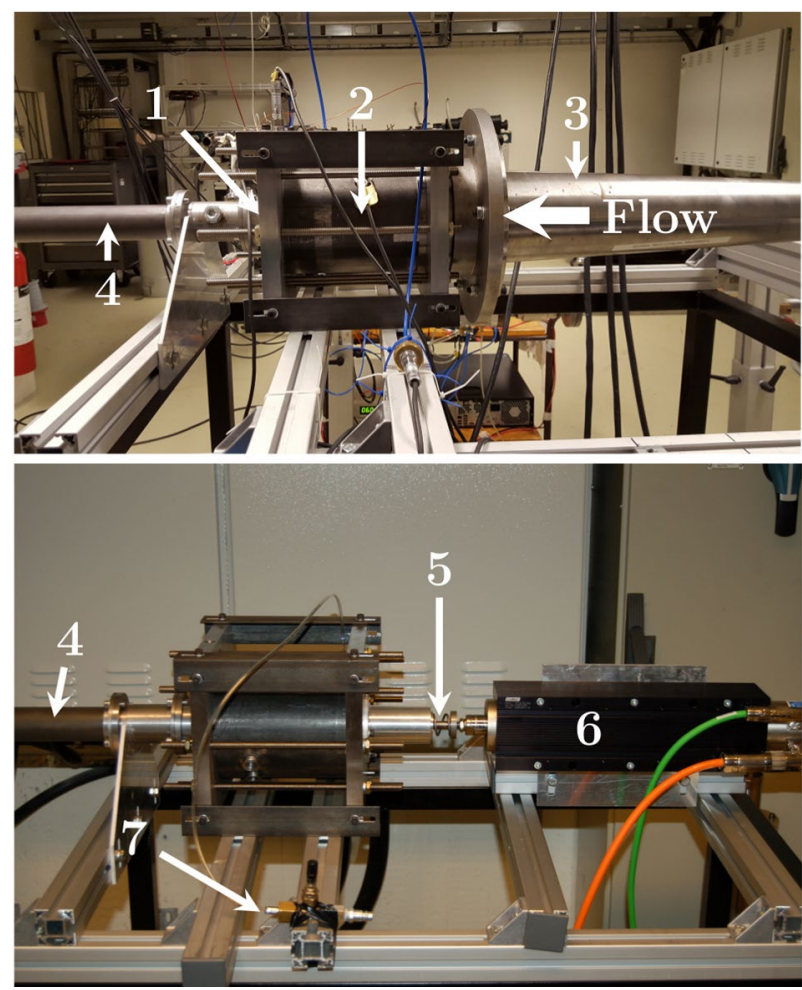

Fig. 1 Photos of the experimental setups (the outlet is to the left in the photos). Top: static valve setup. Bottom: dynamic valve setup. Description: (1) Top plate, (2) Cylinder, (3) Diffuser, (4) Outlet, (5) Spring, (6) Linear motor, (7) Air supply 


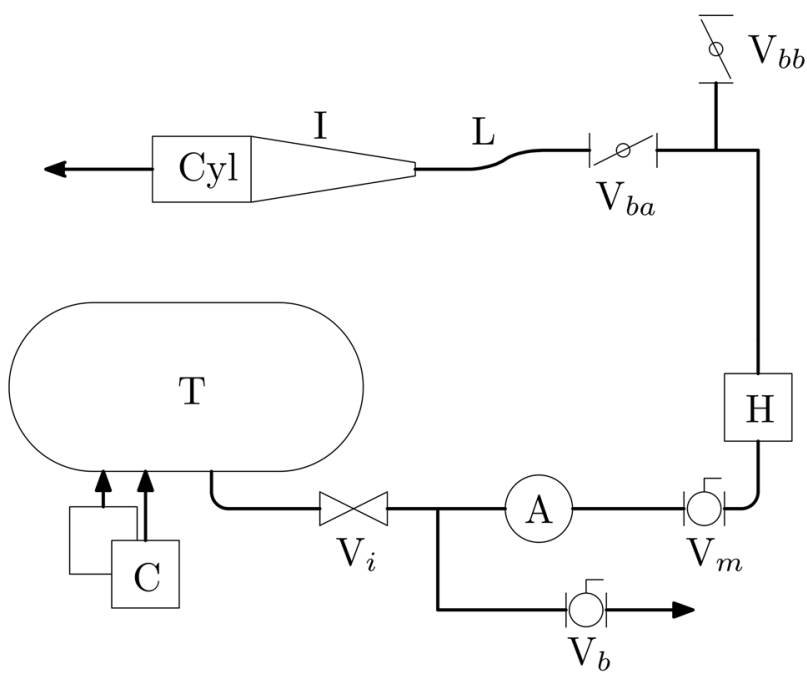

Fig. 2 Schematic sketch of the CICERO laboratory

to the test section) and a bypass branch (used for stabilising the flow through the rig, especially for low flow rates). Two valves regulate the flow through the main and the bypass branches $\left(\mathrm{V}_{\mathrm{m}}\right.$ and $\mathrm{V}_{\mathrm{b}}$, respectively). The flow in the main branch is measured using an ABB FMT500-IG hot-film type mass-flow meter (A), which has an accuracy better than $\pm 0.7 \%$ of the measured mass flow. After this the flow goes through an electric heater (not used in this study, $\mathrm{H}$ in Fig. 2) and out to the two test sites. Two butterfly valves $\left(\mathrm{V}_{\mathrm{ba}}\right.$ and $\mathrm{V}_{\mathrm{bb}}$ ) allow the user to choose which of the sites to use. In these experiments the $7^{\circ}$ conical diffuser (I) was connected to the butterfly valve using a $2 \mathrm{~m}$ long pressure hose $(\mathrm{L})$ with an inner diameter of $50 \mathrm{~mm}$.

The setup of the static rig consisted of a 21 cylinder with a diameter of $B=120 \mathrm{~mm}$ and length $S=177 \mathrm{~mm}$ that was connected to the $7^{\circ}$ conic diffuser through flanges. The cylinder had two taps for Pitot pressure-probes (or static pressure measurements) and two axially co-located taps for total temperature probes (located 0.25 and $0.5 \mathrm{~S}$ from the top plate). In the flange, connecting the cylinder and diffuser, a holder crosses the pipe that allows for the valve actuation rod (VAR) to be locked at any fixed valve lift (Fig. 4 show the dynamic setup, but the connection between the VAR and the valve was similar in both cases).

The top plate had a $45^{\circ}$ "lead in" to a pocket that held a $45^{\circ}$, co-axial valve-seat and a $35 \mathrm{~mm}$ diameter exhaust port (d), whereas the valve had an outer diameter of $\phi=41 \mathrm{~mm}$ and an angle of $45.5^{\circ}$ (see Fig. 3).

The port connected to a $35 \mathrm{~mm}$ diameter straight outlet pipe (approximately $15 d$ long) that exhausted to the atmosphere. The outlet pipe also hosted two $1 \mathrm{~mm}$ pressure taps that were located $2 d$ and $2.5 d$ downstream of the cylinder top. Slightly downstream of the pressure taps the outlet pipe had a tripod guide that fixed the valve stem to the centre of

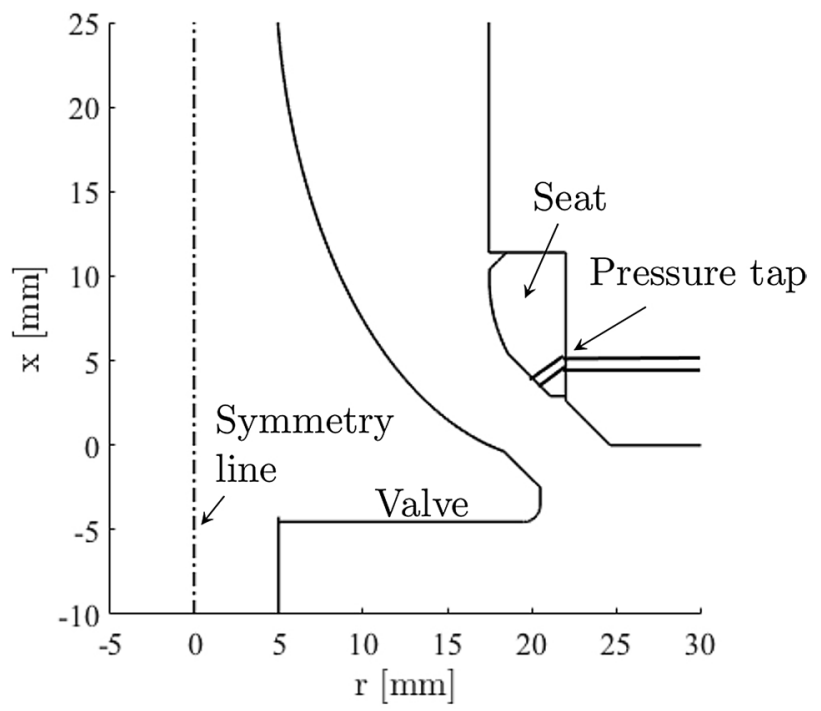

Fig. 3 Sketch of the valve, seat, port and the approximate position of the seat pressure measurement

the pipe. To decrease the aerodynamic blockage the leading and trailing edges of the $1 \mathrm{~mm}$ thick tripod arms and the guide tube (which has a wall thickness of $2 \mathrm{~mm}$ ) were filed at an angle of $30^{\circ}$ with respect to the major axis of the setup.

Although most experiments were made in a single-valve setup an additional top plate was designed and manufactured to accommodate a double-valve geometry since four valves per cylinder, i.e. two inlet and two outlet valves, is the most common configuration in engines today. The centre-to-centre distance between the valves was $45.5 \mathrm{~mm}$ and each valve had its own outlet of the same length as in the single-valve geometry.

All data in the static experiments were acquired with a sampling frequency of $16 \mathrm{kHz}$ for $5 \mathrm{~s}$, using a 16-bit National Instrument PCI-6250 A/D-converter using a LabView program.

The mass-flow rates were set to cover the range of mass flows obtained in the dynamic experiments for a given valve lift.

\subsection{Dynamic valve rig}

For the dynamic valve experiments a cylinder with the same dimensions as in the static valve case $(B=120 \mathrm{~mm} ; S=177$ $\mathrm{mm}$ ) was clamped and sealed between two $20 \mathrm{~mm}$ thick plates (see Fig. 4). The "top plate", where the valve/seat assembly was located, was the same as in the static experiments. The cylinder had three pressure taps (placed 0.25, 0.5 and $0.75 S$ from the cylinder top) and three axially colocated ports for temperature probes. Initial testing of the setup showed negligible difference between the three different cylinder pressure mountings, thus it was decided to use 
Fig. 4 Schematic sketch of the dynamic valve setup

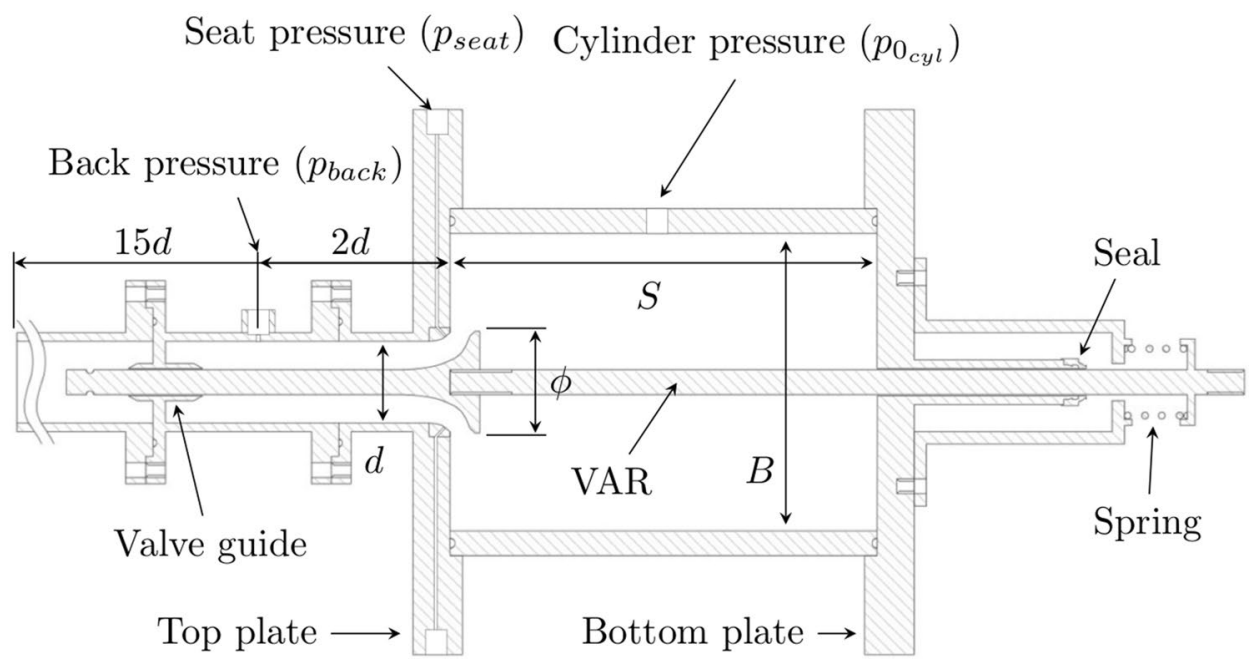

only the centrally placed tap in the experiments. All pressures were measured using Kistler 4045A5 piezoresistive transducers (500 $\mathrm{kPa}$ range), which have a quoted linearity $\leq 0.1 \%$ of full scale output. The temperature was measured using a T-type thermocouple and a Fluke 51-II thermocouple reader, which has an accuracy better than about $\pm 0.3 \mathrm{~K}$. The cylinder was charged prior to exhaustion from a compressed air supply through a solenoid-controlled valve, located near the bottom of the cylinder. The air pressure at start of the exhaustion was varied in the range $300-500 \mathrm{kPa}$.

The top and bottom plate had stadium-shaped sinks (5 $\mathrm{mm}$ deep), in which the cylinder was fitted. This allowed the location of the valve to be moved relative to the cylinder wall, thus allowing the radial position of the valve to be changed. For the experiments in this study the valve was centrally placed in the cylinder. However it was shown that a radial displacement of the valve did not show any significant effect on the outflow characteristics.

To increase the sealing ability in the dynamic experiments, the valve was painted with a rubber spray-paint. This was necessary since obtaining a perfect seal between the valve and the seat is (nearly) impossible without machining the seat to the right shape in situ. The rubber coating had a thickness less than $0.1 \mathrm{~mm}$.

The valve was connected to a LinMot P10-70x320U electromagnetic linear motor, using the valve actuation rod (VAR), which allowed the valve position to be controlled. The VAR passed through the bottom plate via a guide and was sealed using a spring-loaded circular seal. In order for the linear motor to cope with the large forces required to actuate the valve when the cylinder is pressurized, the bottom plate and the VAR compressed a spring during valve closing. The spring generated a force of approximately $300 \mathrm{~N}$ when the valve is fully closed (about half of the force on the valve caused by the pressure difference between the cylinder and the outlet at a cylinder pressure of $500 \mathrm{kPa}$ ).
The valve position was measured using a Novotechnik TE10025 linear transducer that was connected to the slider of the linear motor. The quoted repeatability of the linear transducer is $2 \mu \mathrm{m}$ and the linearity is $\pm 0.2 \%$ of full scale output $(\mathrm{FSO}=25 \mathrm{~mm})$.

As mentioned in Sect. 2.1 two, $1 \mathrm{~mm}$ diameter, pressure taps were located on opposite sides of the valve seat, $0.9 \mathrm{~mm}$ axially downstream from the "leading edge". The taps were connected to the sides of the top plate, through two $3 \mathrm{~mm}$ diameter pressure ports with a length of $68 \mathrm{~mm}$, where two pressure sensors were externally mounted. Such a pressuresensor setup forms a Helmholtz oscillator, which will affect the unsteady pressure measurements. The diameters of the pressure taps were kept large and the lengths of the pressure ports were made as short as possible to minimize damping of the dynamic pressure signal. The setup can be modelled as a $1 \mathrm{D}$ damped oscillator and the pressure can then be described by:

$\frac{d^{2} p_{\mathrm{s}}}{d t^{2}}+2 \zeta \omega_{0} \frac{d p_{\mathrm{s}}}{d t}+\omega_{0}^{2} p_{\mathrm{s}}=\omega_{0}^{2} p$,

where $p_{\mathrm{s}}$ is the pressure the sensor experiences, $p$ is the pressure that one is trying to measure (the seat pressure in this case), $\zeta$ is the damping ratio of the setup and $\omega_{0}$ is the natural frequency (in radians per second) of the setup. The natural frequency of the setup can be estimated with good accuracy using the following relation (see e.g. Bajsić et al. 2007):

$\omega_{0}=a \sqrt{\frac{A_{\mathrm{p}}}{L_{p}\left(V+L_{\mathrm{p}} A_{\mathrm{p}} / 2\right)}}$,

where $a$ is the speed of sound, $L_{\mathrm{p}}$ is the length of the pressure port, $A_{\mathrm{p}}$ is the cross sectional area of the pressure port and $V$ is the end-volume connected to the sensor. The damping ratio is more complicated to estimate, and here it has been 
determined experimentally. This was done using a bursting membrane to generate a pressure step, details of these experiments are given in Winroth (2017b).

When running an experiment, the valve was closed and the cylinder slowly pressurized to the desired initial pressure $\left(p_{0 i}\right)$. When the temperature had stabilized the linear motor was triggered and the valve thereby actuated according to a pre-programmed partial sinusoidal lift-profile equivalent to the lift profile of an engine at a given engine speed $(n)$. The experiments were controlled through LabView and the data were acquired with a sampling frequency of $25 \mathrm{kHz}$. Each case was repeated 8 times and the data were later ensemble averaged.

The initial pressure was varied from $p_{0 i}=300 \mathrm{kPa}$ to $p_{0 i}=500 \mathrm{kPa}$, in steps of $50 \mathrm{kPa}$, and the tested equivalent engine speeds ranged from 800 to $1350 \mathrm{rpm}$.

\subsection{Geometric minimum flow area}

When calculating the isentropic mass flow, to be used for the determination of $C_{\mathrm{D}}$, the throat area $\left(A_{\mathrm{T}}\right)$ is needed (see Eqs. 2, 4). The minimum geometric area is here taken as the throat area and is obtained as the surface area of a conical frustum (see Fig. 5). The distance between the valve and the seat makes the slant height of the frustum $(s)$ :

$s=\sqrt{\left(r_{2}-r_{1}\right)^{2}+\ell^{2}}$,

where $\ell$ is the valve lift, $r_{1}$ is the radius of the valve at the minimum area and $r_{2}$ is radius of the valve seat at the minimum area. The surface area is then calculated using the following expression:

$A_{T}=\pi\left(r_{1}+r_{2}\right) s=\pi\left(r_{1}+r_{2}\right) \sqrt{\left(r_{2}-r_{1}\right)^{2}+\ell^{2}}$.

The throat area is found numerically using the valve-port outlet geometry and Eq. 8. The area is plotted as a function of valve lift in Fig. 6.

When the valve initially lifts from the seat the location of the throat moves from the seat-valve contact point to the back of the conic section of the valve and connects orthogonally to the conical section of the seat. For valve

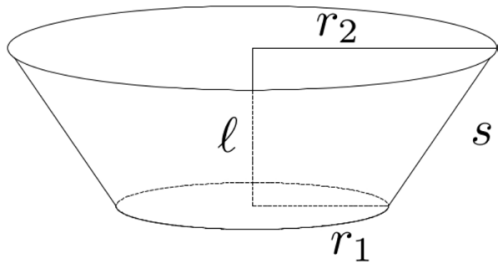

Fig. 5 Conical frustum

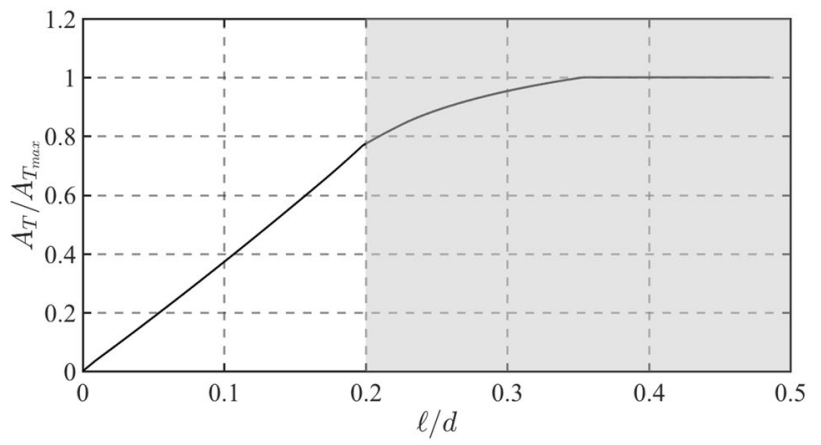

Fig. 6 Minimum geometrical flow area for the single-valve setup as a function of valve lift (the shaded area is outside of the range of interest in this study)

lifts $0.014<\ell / d<0.17$ the throat moves upstream towards the seat leading edge connecting to the back of the valve conic section. By further increasing the lift in the range $0.17<\ell / d<0.198$ the location of the throat is fixed at the leading edge of the seat-conic section and the back of the valve-conic section. In this range only the angle of the frustum is changing. As the lift is increased further, the position of the throat "jumps" back to the trailing edge of the conic section of the seat and now starts to move downstream on the valve. Figure 7 shows the location of the throat for five valve lifts in the range $0.114 \leq \ell / d \leq 0.229$. Finally, at $\ell / d \geq 0.354$ the minimum area is at the valve guide in the outlet pipe.

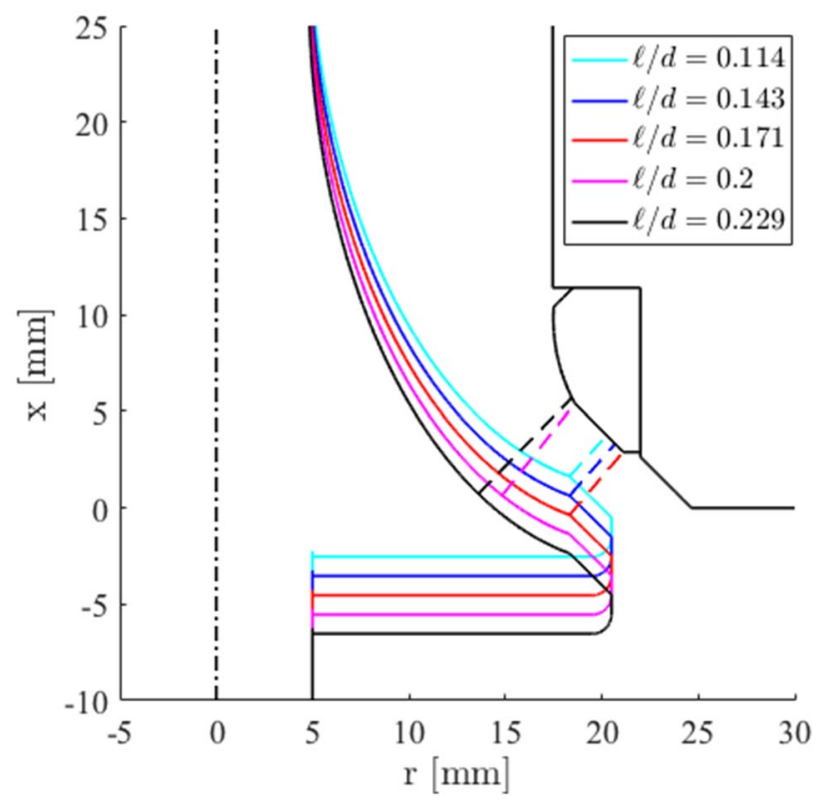

Fig. 7 Valve and port geometry for valve lifts ranging $0.114 \leq \ell / d \leq 0.229$. The dashed lines marks the minimum geometrical flow area. For location of the pressure tap see Fig. 3 
Since the location of the throat is changing, it is not possible to measure the true throat pressure with only one pressure tap at a fixed position. This means that the throat area cannot be used for $C_{\mathrm{D}}$ calculations for subsonic flows. It also implies that the seat pressure $\left(p_{\text {seat }}\right)$, which is measured 0.9 $\mathrm{mm}$ from the leading edge of the conic section of the seat, cannot be directly used as a "check" to decide if the flow is choked or not.

When the location of the throat "jumps" from the seat leading edge to the back, $p_{\text {seat }}$ should experience an abrupt change in pressure. This is due to the change in pressure from measuring downstream of the throat (region of potential supersonic velocities) as compared to measuring upstream of the throat where $p_{\text {seat }}>0.528 p_{0}$.

\subsection{Time-resolved mass-flow measurements}

To compute $C_{\mathrm{D}}$ for the dynamic valve system, it is necessary to temporally resolve the mass flow during the discharge process. Time-resolved mass-flow measurements in pipe flows can be done by traversing a hot-wire probe over the cross sectional area of the pipe (Laurantzon et al. 2012) or by using a vortex-shedding meter (Ford et al. 2016). However, if $C_{\mathrm{D}}$ is to be correlated to a certain lift, it is necessary to place the mass-flow meter very close to the valve itself. This is because the density may vary along the outlet pipe, and thus the time lag of the measurement relative to the lift becomes unknown.

It is, however, possible to determine the mass of the air that has left the cylinder using the cylinder pressure (see e.g. Povey and Beard 2008). The mass of air contained in the cylinder is determined using the ideal gas law:

$m(t)=\frac{V p(t)}{R T(t)}$,

where $m$ is the mass of the air in the cylinder, $V$ is the cylinder volume, $p$ and $T$ are the pressure and temperature of the air in the cylinder, respectively. To be able to use Eq. (9) directly it is necessary to measure both the time-resolved pressure as well as temperature. Although measuring timeresolved pressure is considered an easy task (with a flushmounted pressure sensor), measuring temporally resolved temperature is not. This is usually accomplished using a cold-wire resistance thermometer, which can have a relatively high roll-off frequency (dependent on the wire length and diameter, Arwatz et al. 2013). When the temperature change is large, however, as in the present experiments $(\Delta T \approx 100 \mathrm{~K}$ ) the thermal inertia of the prongs significantly influences the measurement accuracy, rendering cold-wire anemometry unusable for the present case.

The expansion of the air in the cylinder during the exhaustion can, however, be viewed as an isentropic process
(Semlitsch et al. 2015; Povey and Beard 2008). Thus, the temperature is related to the pressure as follows:

$\frac{p_{1}}{p_{2}}=\left(\frac{T_{1}}{T_{2}}\right)^{\gamma /(\gamma-1)}$,

where the subscripts 1 and 2 refer to two instances in time. Equation (10) can thus be used to calculate the time resolved temperature:

$T(t)=T_{0 i}\left[\frac{p(t)}{p_{0 i}}\right]^{(\gamma-1) / \gamma}$,

where $T_{0 i}$ and $p_{0 i}$ are the initial total temperature and pressure, respectively. If Eq. (11) is used in Eq. (9) and differentiated with respect to time the following relationship is found for the time-resolved mass flow:

$\dot{m}=\left|\frac{d m}{d t}\right|=\frac{V}{\gamma R T_{0 i}}\left(\frac{p_{0 i}}{p}\right)^{(\gamma-1) / \gamma}\left|\frac{d p}{d t}\right|$.

where $\dot{m}=\dot{m}_{\text {actual }}$. As an example Fig. 8 shows the cylinder pressure measurement and the mass flow calculated from this pressure trace, for a valve-opening time corresponding to an engine speed of $900 \mathrm{rpm}$ with an initial cylinder pressure of $p_{0 i}=500 \mathrm{kPa}$. The cylinder pressure is seen to decrease monotonously with time as expected, whereas the mass flow rate has a maximum at about $14 \mathrm{~ms}$ and then a hump around $20 \mathrm{~ms}$. The analysis of the experimental results is limited to valve lifts smaller than $\ell / d<0.2$ (i.e. smaller than $7 \mathrm{~mm}$ ) which corresponds to the blowdown phase, i.e. there is no pumping work performed by the piston. For the case shown in Fig. $8, \ell / d=0.2$ occurs around $10 \mathrm{~ms}$, so the analysis deals with the phase of increasing flow rate. However, the hump observed is still of interest and it can be inferred that it occurs when the flow goes from being supersonic to fully subsonic which would decrease flow losses. Although not shown here the absolute value of the pressure derivative has a local minimum at that position and for all different engine speeds and initial pressures this minimum occurs at approximately the same ratio between the initial cylinder pressure and the pressure at the minimum, a value which is slightly less than 2 .

\section{Results}

The results of the static single-valve experiments are presented in Sect. 3.1. In Sect. 3.2 the data from the dynamic single-valve experiments are presented and discussed.

Since there is no piston in the setup, the model experiments are only valid during the blowdown phase. Thus, the analysis will only consider $\ell / d \leq 0.2$, corresponding to $\ell<7 \mathrm{~mm}$, for which typically the piston is near the 
Fig. 8 Example of cylinder pressure trace (left) and calculated mass flow (right). Case: $900 \mathrm{rpm}$ with $500 \mathrm{kPa}$ initial cylinder pressure
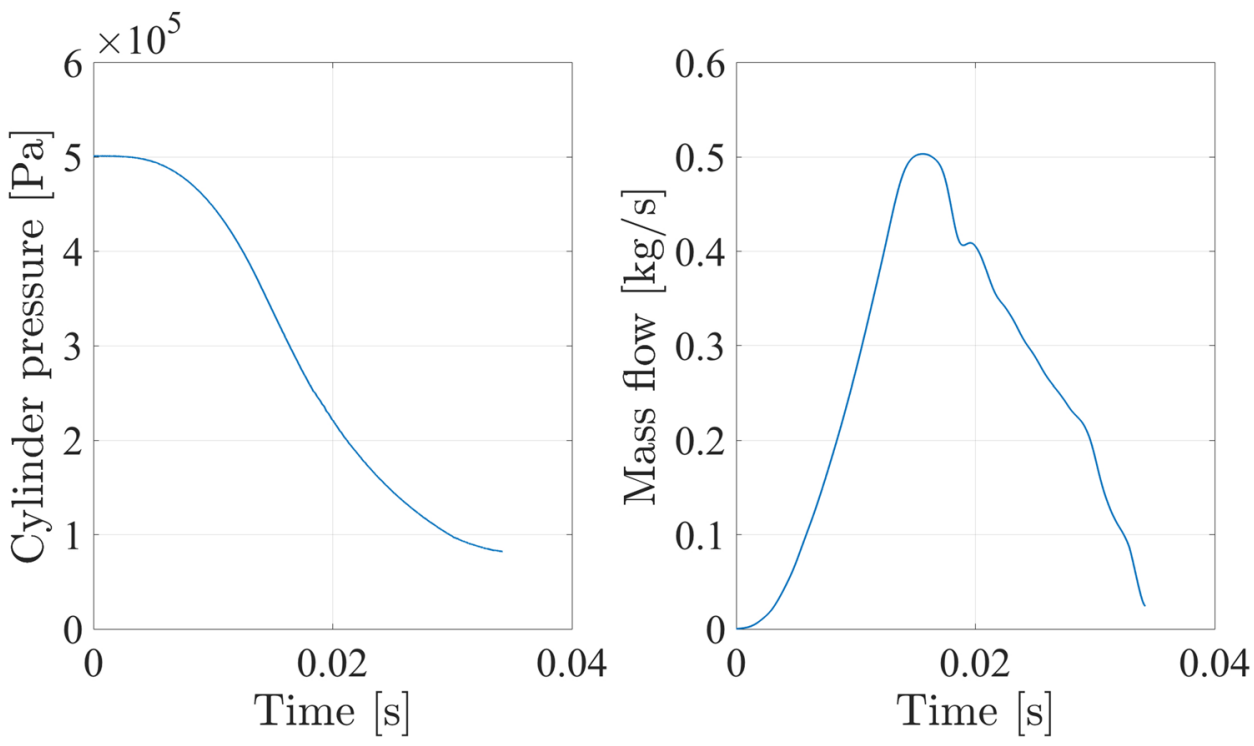

bottom-dead centre, i.e. there is no pumping work done. In figures with lifts $\ell / d>0.2$, the region where $\ell / d>0.2$ is shaded to indicate that this region is not part of the main focus of the analysis.

\subsection{Static single-valve experiments}

In the experiments the position of the minimum geometric area (i.e. the throat position) moves as a function of the valve lift. Therefore, it is not possible to monitor the corresponding throat pressure. However, if the flow is choked, the ratio of total to throat pressure is fixed at $p_{0} / p_{T}=1.89$. Thus, the isentropic mass flow, for choked conditions, can be calculated without measuring the throat pressure (see Eq. 4). This means that the flow must be choked when using the minimum geometric flow area as the reference area for calculations of $C_{\mathrm{D}}$.

To check if the flow is choked the seat pressure was studied. If the flow is choked the pressure ratio $p_{0} / p_{\text {seat }}$ should be constant. The pressure ratio is determined by the ratio of local flow area at the measurement location to the minimum flow area (Anderson 2004). Any change in this ratio is associated with an upstream change in effective area (total pressure loss or change in flow topology, such as the appearance of separation bubbles).

In Fig. $9 p_{0 \text {,cyl }} / p_{\text {seat }}$ is plotted as a function of the cylinder total pressure. It can be seen in this figure that the flow chokes for a cylinder total pressure somewhere in the range $158<p_{0 \text {,cyl }}<193 \mathrm{kPa}$. At the three smallest valve lifts the pressure tap is upstream the throat (the pressure ratio is below the critical value of 1.89), whereas for higher lifts the throat section moves upstream and passes the pressure tap, which hence moves downstream the throat. As can be seen in the figure the pressure ratio decreases slightly with

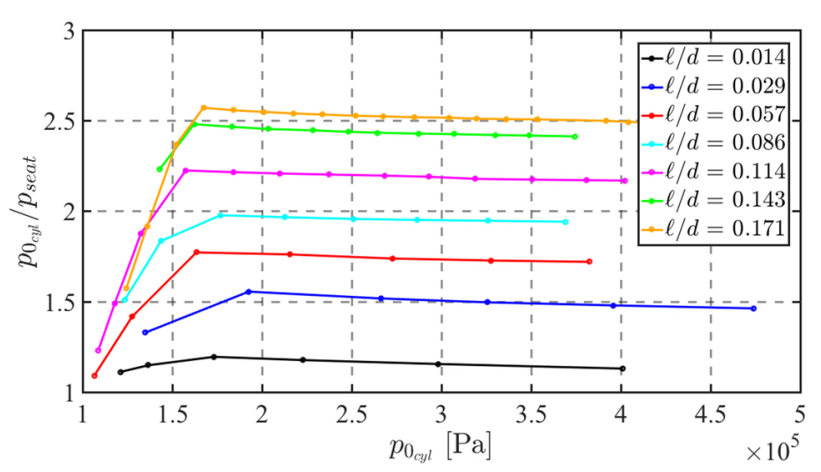

Fig. 9 Ratio of cylinder total pressure over seat pressure as a function of cylinder total pressure

increasing cylinder pressure in the choked state, indicating that the Mach number at the position of the pressure transducer decreases. At least two competing influences will affect the flow conditions in the seat area; one would expect thinner boundary layers at the higher stagnation pressure since the laminar boundary layer thickness is proportional to $\sqrt{\mu / \rho}$ and $\mu$ is independent of pressure whereas $\rho$ increases with pressure. Also local separation regions might be affected (size and location) as the dynamic pressure increases $\left(\rho u^{2} / 2\right)$.

The discharge coefficient, for the tested valve lifts, is shown in Fig. 10 as a function of cylinder total pressure (all of which are in choked condition). Since the flow is supersonic downstream the throat the mass flow past the valve only depends on the minimum flow area and the total pressure at that position. It can be seen that the value of $C_{\mathrm{D}}$ increases with the valve lift. This can be understood by the fact that the contraction becomes less aggressive as the valve lift is increased and thus the associated flow losses are 


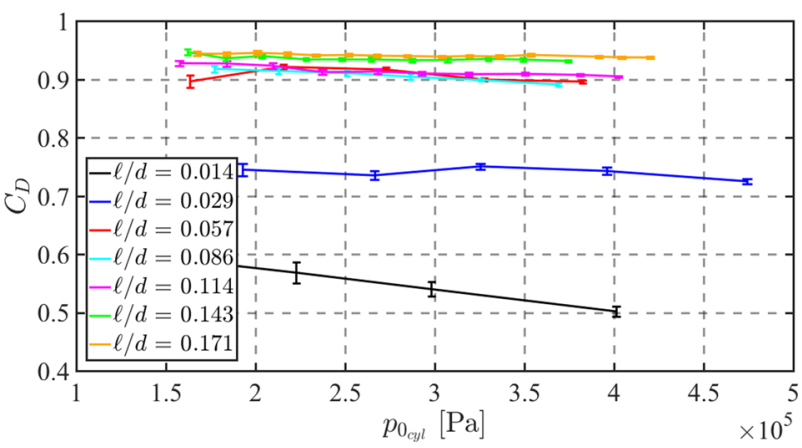

Fig. $10 C_{\mathrm{D}}$ as a function of cylinder total pressure (only choked conditions are plotted). Error bars mark the $95 \%$ confidence interval based on the standard deviation of the measurements

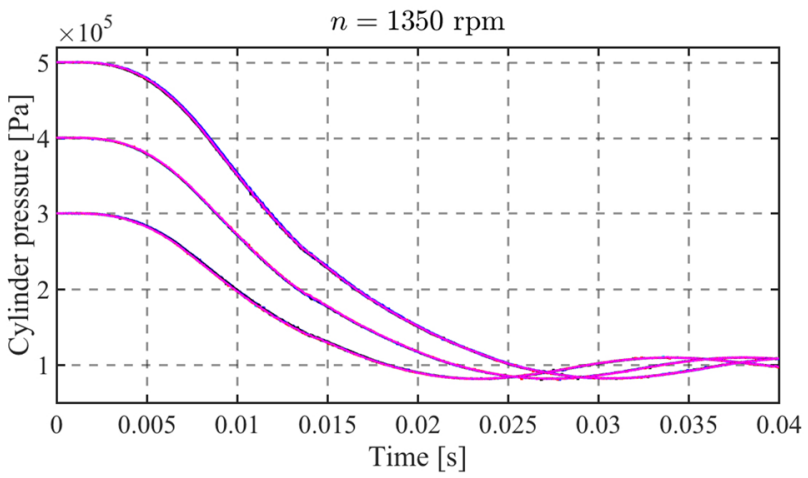

Fig. 11 Cylinder pressure for each trial ( 8 for each case) for an equivalent engine speed of $1350 \mathrm{rpm}$, with $p_{0 i}=300,400,500 \mathrm{kPa}$

decreased. In addition, as the flow area increases the ratio of the wetted surface to the flow area will decrease, and thus decrease the influence of friction. As can be seen, except for the smallest valve lift, the value of $C_{\mathrm{D}}$ is almost independent of the cylinder pressure.

\subsection{Dynamic single-valve experiments}

The dynamic experiments are carried out by first filling the cylinder with air to the desired pressure, wait until the temperature stabilise whereafter the valve rod is actuated with the desired lift profile. For each parameter setting (pressure and equivalent rotational speed) the experiments were repeated eight times. To demonstrate the repeatability of the experiments, and to give the reader an impression of the signal-to-noise ratio, the raw pressure signals of the eight trials, for three different initial pressures, for an equivalent engine speed of $1350 \mathrm{rpm}$ are shown in Fig. 11. Valve lift measurements, corresponding to engine speeds of 900 and $1350 \mathrm{rpm}$ at an initial cylinder pressure of $400 \mathrm{kPa}$ are shown in Fig. 12. Although some small-scale noise persists,

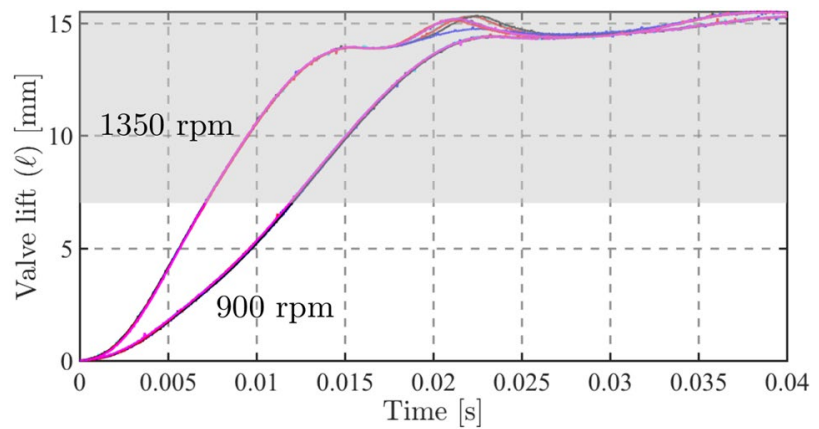

Fig. 12 Valve lift profile for each trial for an equivalent engine speed of 900 and $1350 \mathrm{rpm}$ with $p_{0 i}=400 \mathrm{kPa}$

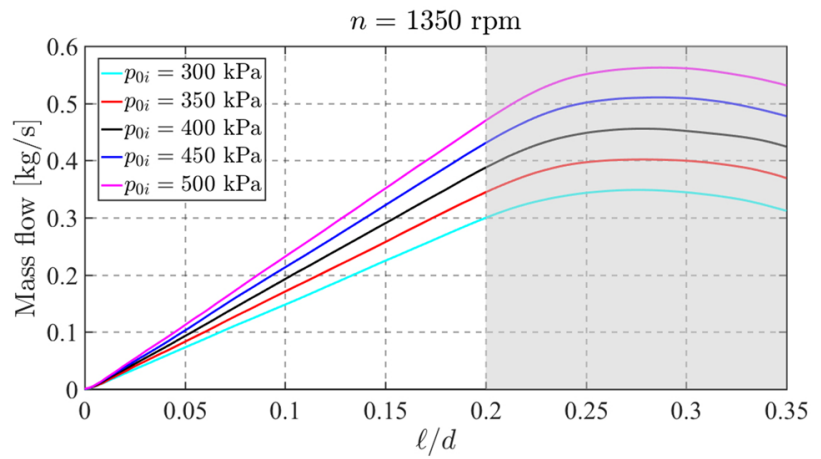

Fig. 13 Mass flow rate for different initial cylinder pressures as a function of valve lift for an equivalent engine speed of $1350 \mathrm{rpm}$

the profiles are consistent and repeatable. This noise originates from electrical interference, generated by the linear motor used to actuate the valve. To improve the signal-tonoise ratio, for each case 8 trials were ensemble averaged.

In the $1350 \mathrm{rpm}$ case a noticeable discrepancy in the valve lift profile can be seen at around 18-25 ms (see Fig. 12). This is caused by the active control of the linear motor, however, this deviation occurs at valve lifts in excess of those of interest in this study.

The normalised demand lift profile is the same for all engine speeds. Evaluating the difference $\epsilon=\left(\ell_{d}-\ell\right) / d$, where $\ell_{d}$ is the demanded lift, it is possible to compare the different engine-speed lift profiles. Evaluating $\epsilon$ for all test cases it is found $-0.032 \leq \epsilon \leq 0.027$ for $\ell / d \leq 0.2$, indicating that the different engine speeds have similar (though not perfectly matched) normalised lift profiles.

As an example, Fig. 13 shows the mass flow as a function of valve lift $(\ell / d)$ for engine speeds of $1350 \mathrm{rpm}$, for the different initial cylinder pressures.

As discussed in Sect. 3.1 a condition for the calculations of the isentropic mass flow is that the flow is choked. Determining if the flow is choked is non-trivial in the dynamic experiment, since the local flow area at the seat pressure 


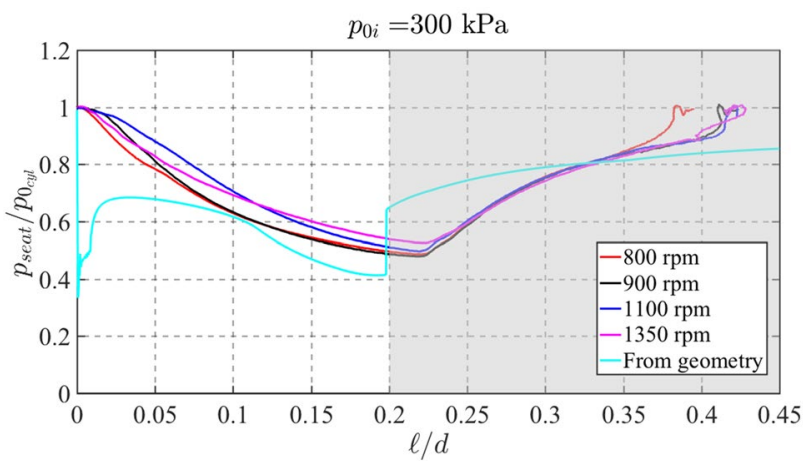

Fig. 14 Seat-to-cylinder pressure ratio versus valve lift for the different equivalent engine speed with an initial cylinder pressure of $300 \mathrm{kPa}$

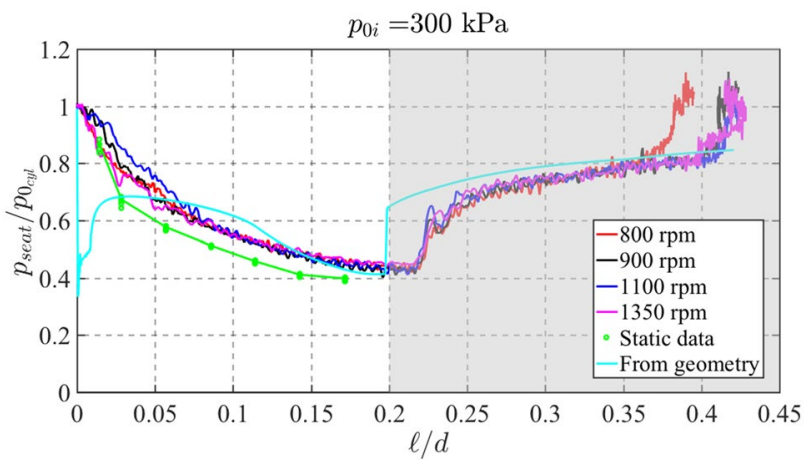

Fig. 15 Corrected seat-to-cylinder pressure ratio versus valve lift for the different equivalent engine speed with an initial cylinder pressure of $300 \mathrm{kPa}$

measurement is continuously changing. Instead the measured pressure ratio $p_{0_{\text {cyl }}} / p_{\text {seat }}$ can be compared to the pressure ratio estimated from the ratio of the minimum geometrical area and the area at the seat measurement position. The case which should reach sub-critical condition at the lowest valve lift is the $p_{0 i}=300 \mathrm{kPa}$ case at an equivalent engine speed of $n=800 \mathrm{rpm}$. Figure 14 shows the measured pressure ratio of the different engine speeds for an initial cylinder pressure of $p_{0 i}=300 \mathrm{kPa}$. This figure show a discrepancy between the measured pressure ratio and the pressure ratio estimated from the geometry. However, this deviation is mainly a result of the "installation" of the pressure sensor.

The setup for the seat-pressure measurement was found to be overdamped. The damping was found to be $\zeta=3.5$ and the eigenfrequency $\omega_{0}=5400 \mathrm{rad} / \mathrm{s}$ (Winroth $2017 \mathrm{~b}$ ). Using these values and Eq. (5) the pressure measurement can be corrected to better reflect the pressure in the seat, see Fig. 15. Since Eq. (5) depends on both the first and second time-derivative of the pressure measurement signal noise is amplified. This means that the corrected seat-pressure is not suitable as a quantitative indicator of the seat pressure, but it is still useful for determining if the flow is choked.

In Fig. 15 the pressure traces for all engine speeds collapse nicely except for large $\ell / d$. The step in the pressure, which reflects the fact that the throat area moves from the front to the back of the seat (see Fig. 7), is seen to occur for a larger $\ell / d$ than the geometry itself implies. This is probably due to the fact that the physical geometry does not truly represent the effective flow geometry due to boundary layers and maybe separation. Also shown are the corresponding static measurements which show a consistent slightly smaller pressure ratio as compared to the dynamic cases. This may be due to separated regions which in the steady case are developed as compared to that of the developing separations in the dynamic measurements; giving a smaller flow area, a higher Mach number and thereby a lower pressure ratio. As is well known a pressure ratio below 0.528 indicates supersonic flow at the pressure tap location and as can be seen there is a smooth transition from subsonic to supersonic conditions at the pressure tap. At large valve lifts $(\ell / d>0.32)$ the pressure trace deviates from the trend line specified from the geometry. This deviation indicates that the flow is no longer choked, however the flow is choked for all valve lifts in the range of interest $(\ell / d \leq 0.2)$.

Figure 16 shows $C_{\mathrm{D}}$ as a function of $\ell / d$, where each graph shows $C_{\mathrm{D}}$ for the different initial cylinder pressures for one engine speed together with the static values of $C_{\mathrm{D}}$. The different initial pressures gives different mass flows at a given $\ell / d$ and the static values were obtained for a span of mass flows corresponding to those in the dynamic experiments. As can be seen the variation in $C_{\mathrm{D}}$ with mass flow in the static experiments is rather small (same data is in Fig. 10). For the dynamic experiments all $C_{\mathrm{D}}$ curves have similar profiles, with an approximately logarithmic shape at low valve lifts leading into a more linearly increasing region when $\ell / d$ increases. Lower $p_{0 i}$ cases result in higher values of $C_{\mathrm{D}}$, whereas $C_{\mathrm{D}}$ is less sensitive to changes in cylinder pressure as the engine speed increases.

Figure 17 shows the variation of $C_{\mathrm{D}}$ as a function of $\ell / d$ for various engine speeds at a constant initial cylinder pressure $\left(p_{0 i}=500 \mathrm{kPa}\right)$. As the engine speed is increased, $C_{\mathrm{D}}$ is likewise increased. This is quite surprising, since one would expect that the slowest engine speed should be most similar to the static case (assuming that as $n \rightarrow 0$ the valve behaviour likewise tends to the static case). As this is not the case, there is clearly a fundamental difference between the static and dynamic exhaust processes.

To clearly illustrate the changes in flow physics between the static and dynamic cases Fig. 18 shows the pressure ratio of the cylinder pressure and the back pressure measured in the outlet pipe for various cylinder pressures with $\ell / d=0.143$. The figure shows results both for the steady case as well as for the four different engine speeds used in 

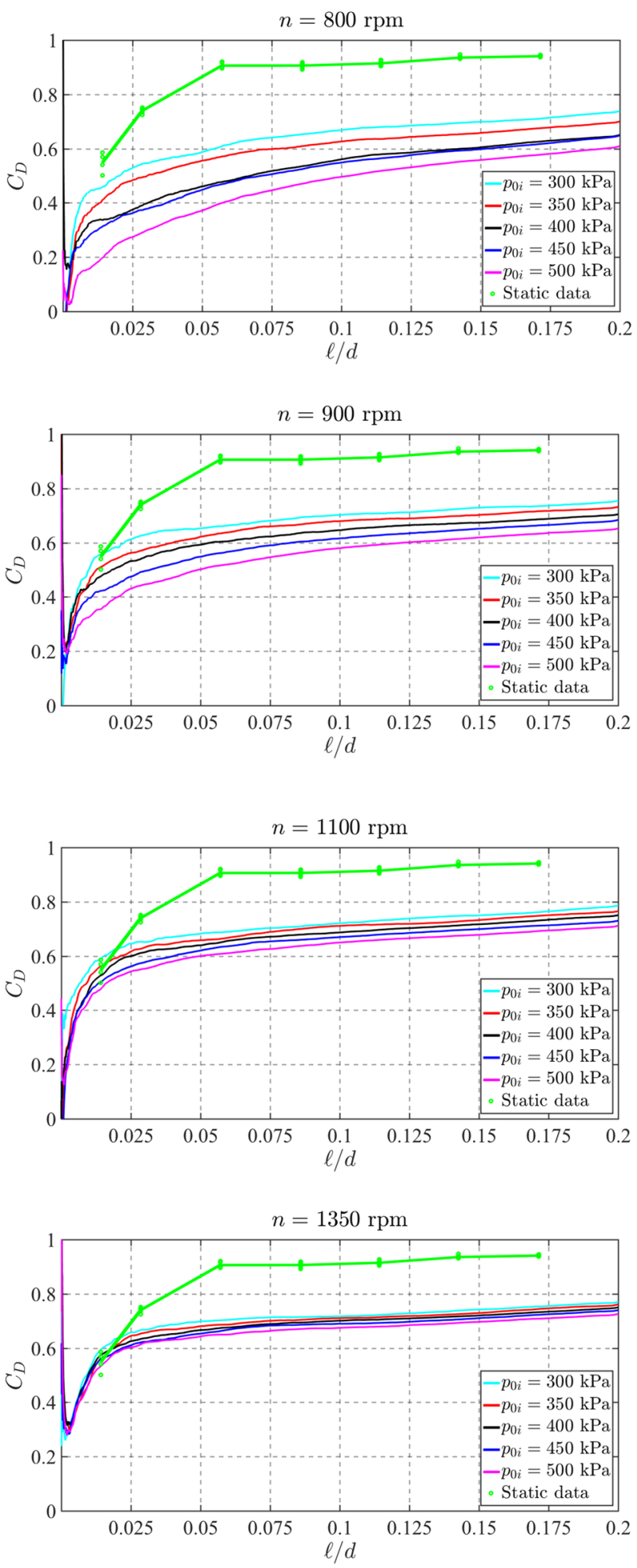

Fig. 16 Dynamic discharge coefficient as a function of valve lift

this study. In the steady case a transition is clearly seen at a cylinder pressure around $240 \mathrm{kPa}$, where the back pressure

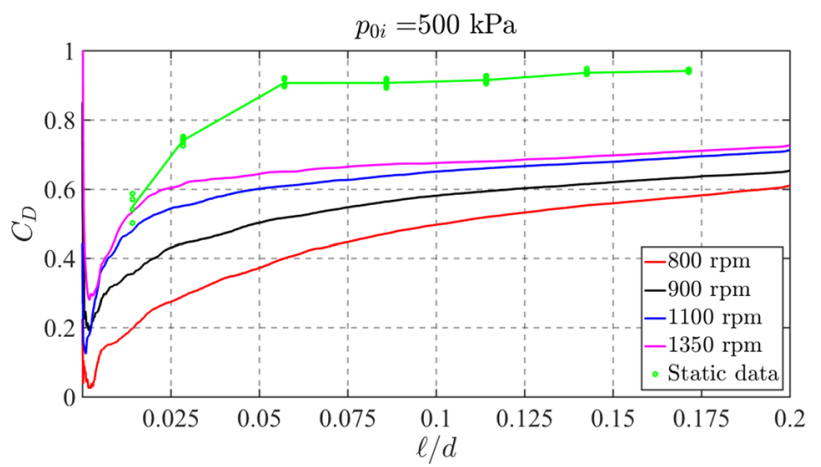

Fig. 17 Comparison of dynamic (for an initial cylinder pressure of $500 \mathrm{kPa}$ ) and static $C_{\mathrm{D}}$ as a function of valve lift. For the static cases all mass-flow rates, for which the flow is choked, are plotted and the solid green line marks the average value of the static $C_{\mathrm{D}}$

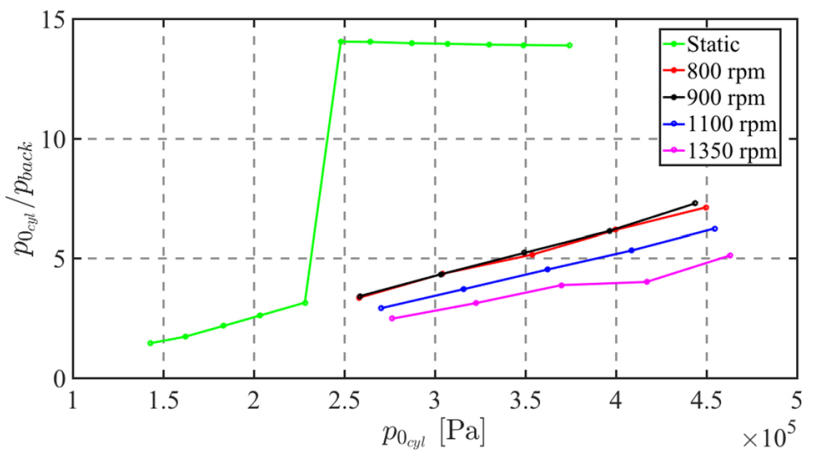

Fig. 18 Pressure ratio between cylinder pressure and back pressure in the exhaust pipe at a valve lift of $\ell / d=0.143$ for static as well as dynamic measurements

becomes small and the ratio becomes constant independent of the cylinder pressure, indicating a supersonic flow at the position of the pressure tap. This pressure ratio of about 14 indicates a Mach number of about 2.4 and an area ratio of 2.3 if the flow was isentropic. However, for $\ell / d=0.143$ the area ratio between the exhaust pipe area at the position of the pressure tap and the open valve seat area is 1.72 which would give a Mach number of 2.0. This difference may be explained by losses (such as oblique shock waves) in the flow giving a lower total pressure in the outlet pipe than the isentropic one.

For the dynamic cases no such transition is seen, instead the pressure ratio increases linearly with increasing cylinder pressure. The higher the engine speed the lower the pressure ratio, however, in all cases the flow is supersonic in the valve region, indicating that the flow becomes subsonic downstream the valve seat by passing through one or several shocks. 


\section{Discussion}

The statically derived $C_{\mathrm{D}}$ overpredicts $C_{\mathrm{D}}$ of the dynamic discharge process. This means that a simulation based on a statically obtained $C_{\mathrm{D}}$ (i.e. assuming quasi-steady behaviour) will not accurately estimate the mass flow. This is illustrated in Fig. 19, where the cylinder discharge has been simulated using the statically obtained values of $C_{\mathrm{D}}$ and is compared to the measured mass flow out of the cylinder. Since the simulated mass flow is overestimated the pressure pulse that travels through the exhaust tract will have the wrong shape. This will affect all calculations made for the engine system, e.g. the working point of the turbine which directly affects the compressor or pumping losses of the engine.

\subsection{A measure of steadiness}

To understand why the dynamic and static cases differ, it is necessary to reapproach the problem. Clearly the exhaust process is not quasi-steady as a dependence on $n$ exists. However, as the faster $n$ cases yield increased $C_{\mathrm{D}}$ values it is also apparent that considering the valve motion alone (relative to some characteristic velocity) does not provide a complete picture of the problem. This calls into question the conventional reasoning that the process is quasi-steady because $d \ell / d t<<\sqrt{\gamma R T}$. Further it raises the questions, what is governing the exhaust process? Is there another way to determine if the process is quasi-steady or not?

To understand the exhaust process, let us first consider the differences between a dynamic and static experiment. One of the major differences between the static and the dynamic experiments is that in the dynamic experiment the air in the cylinder will accelerate from nominally stagnant conditions, whereas in the static experiments the air flow is steady. This

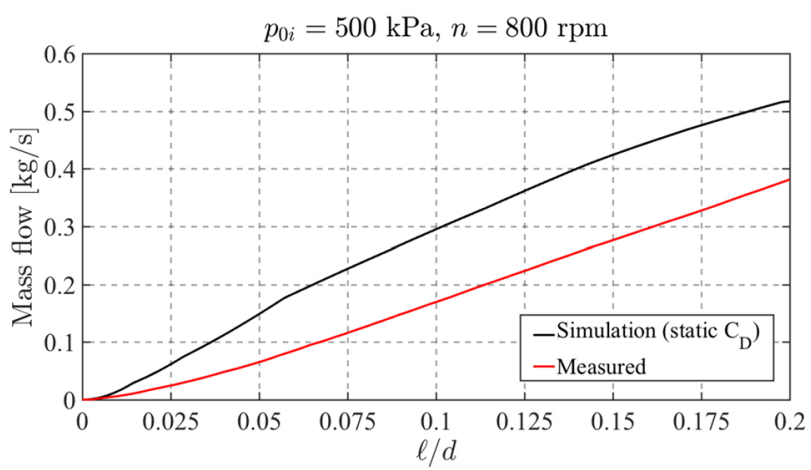

Fig. 19 Mass flow calculation of the exhaust process, using a $0 \mathrm{D}$-model for an initial cylinder pressure $p_{0 i}=500 \mathrm{kPa}$ and an equivalent engine speed $n=800 \mathrm{rpm}$. The red line shows the measured mass flow and the black line shows the simulated mass flow using the static $C_{\mathrm{D}}$ means that the inertial effects from accelerating the flow will be different in the two types of experiments. However, if this was the sole cause of the change in $C_{\mathrm{D}}$, increasing engine speed should decrease $C_{\mathrm{D}}$, which clearly it does not.

The conventional approach assumes the discharge process to be quasi-steady because the valve speed $[\mathcal{O}(1)(\mathrm{m} / \mathrm{s})]$ is much smaller than the characteristic flow speed $\left[\mathcal{O}\left(10^{2}\right)\right.$ $(\mathrm{m} / \mathrm{s})]$. Hence, the flow essentially perceives the valve as stationary.

The relation between the characteristic speeds, used in the conventional approach, is a necessary requirement. However, that approach neglects the dynamics of the flow conditions, which are (for a cylinder discharge process) also continuously changing.

Instead, both the geometry and the flow conditions should be considered. If the relative rate of change in flow conditions is sufficiently small for the time spent at any given valve lift the process may be quasi-steady. In other words, if the time scale of the flow conditions in the cylinder $\left(\tau_{\mathrm{c}}\right)$ is much larger than the time scale of the valve geometry $\left(\tau_{\mathrm{g}}\right)$, and the time scale of the valve geometry is much larger than the time scale of the flow $\left(\tau_{\mathrm{f}}\right)$ the process should be quasi-steady:

$\tau_{f}<<\tau_{\mathrm{g}}<<\tau_{\mathrm{c}}$.

For the exhaustion process of an engine the condition of $\tau_{\mathrm{f}}<<\tau_{\mathrm{g}}$ will always be true since the typical valve speeds are 2 orders of magnitude smaller than the speed of sound $\sqrt{\gamma R T}$. We can estimate the time scale of the geometry change as $\tau_{\mathrm{g}}=A_{\mathrm{T}} / \dot{A}_{\mathrm{T}}$ whereas the flow conditions $(p, T)$ are dictated by the amount of air in the cylinder and the associated time scale can thus be expressed as $\tau_{\mathrm{c}}=m / \dot{m}$. Here, $\dot{A}_{\mathrm{T}}$ is the time-derivative of the minimum area. The time scales associated with these values may be used to establish an additional criterion for the validity of the quasi-steady assumption, for dynamic exhaustion processes

$Q_{\mathrm{S}}=\frac{\tau_{\mathrm{c}}}{\tau_{\mathrm{g}}}=\frac{\dot{A}_{\mathrm{T}} / A_{\mathrm{T}}}{\dot{m} / m}$,

For a transient process $Q_{\mathrm{S}}>>1$ should mean that the process could be considered as quasi-steady. The numerator in Eq. (14) can be written as:

$\frac{\dot{m}}{m}=\frac{\rho^{*} A^{*} \sqrt{\gamma R T^{*}}}{\rho_{0} V}=\frac{R T_{0} A^{*} \frac{\rho^{*}}{\rho_{0}} \rho_{0} \sqrt{\gamma R \frac{T^{*}}{T_{0}} T_{0}}}{p_{0} V}$,

where the asterisk denotes values at sonic conditions. The ratios $\rho^{*} / \rho_{0}$ and $T^{*} / T_{0}$ are constant. The cylinder total temperature $\left(T_{0}\right)$ can be written as a function of the cylinder pressure $\left(p_{0}\right)$ using Eq. (10) and the cylinder total density can be rewritten in terms of pressure and temperature using the ideal gas law. After some algebra Eq. (15) becomes: 
$\frac{\dot{m}}{m}=C \frac{A^{*} \sqrt{\gamma R T_{0 i}}}{V}\left(\frac{p_{0}}{p_{0 i}}\right)^{\frac{\gamma-1}{2 \gamma}}$

where

$C=\left(\frac{2}{\gamma+1}\right)^{(\gamma+1) /[2(\gamma-1)]}$.

Using Eqs. (16) in (14) and letting $A^{*}=A_{\mathrm{T}}$ the following expression is found for $Q_{S}$ :

$Q_{\mathrm{S}}=\frac{1}{C}\left(\frac{p_{0 i}}{p_{0}}\right)^{(\gamma-1) / 2 \gamma} \frac{V}{A_{\mathrm{T}} \sqrt{\gamma R T_{0 i}}} \frac{\dot{A}_{\mathrm{T}}}{A_{\mathrm{T}}}$,

As stated above, the exhaust process can be considered quasi-steady if $Q_{\mathrm{S}}>>1$ (exactly how large is not clear but 2-3 orders of magnitude would seem logical).

For a large ratio $V / A_{\mathrm{T}}^{3 / 2}$ the flow is expected to be quasisteady. If the flow area is small only a small amount of air will leave the cylinder for a given lift. Likewise, if the volume is large the discharged air (at any given valve lift) will only have a small effect on the (cylinder) conditions.

In the experiments performed in this study a fixed volume is used. Thus, it is expected that the initial part of the exhaust process is most likely to be quasi-steady (as the flow area scales with valve lift).

Figure 20 shows $Q_{\mathrm{S}}$ as a function of valve lift, for an initial pressure $p_{0 i}=500 \mathrm{kPa}$. It can be seen that $Q_{\mathrm{S}}$ rapidly decreases with increasing valve lift and that $Q_{\mathrm{S}}<10^{2}$ at $\ell / d>0.029$ for all engine speeds tested in this campaign. Referring to Fig. 17 it can be seen that the static and dynamic $C_{\mathrm{D}}$ have similar values at high $Q_{\mathrm{S}}$-numbers, i.e. at small $\ell / d$. The $Q_{\mathrm{S}}$-number increases with engine speed, a trend that also can be seen in Fig. 17 where higher engine speeds moves the obtained $C_{\mathrm{D}}$ curves towards the one obtained from steady measurements. This indicates,

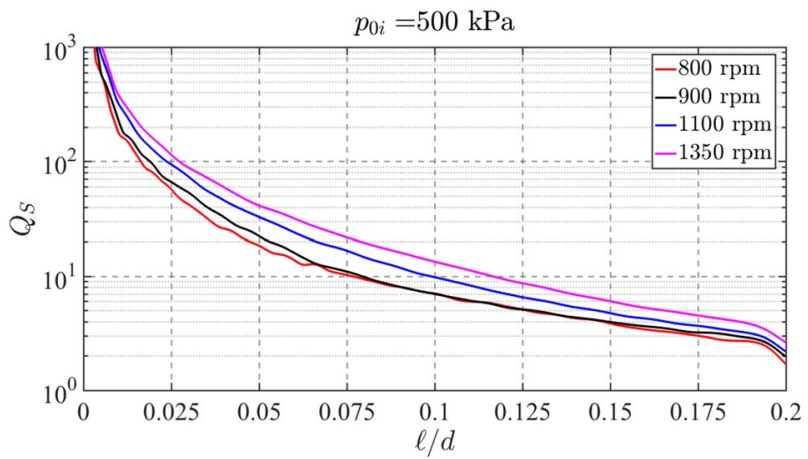

Fig. $20 Q_{\mathrm{S}}$ as a function of valve lift for an initial cylinder pressure $p_{0 i}=500 \mathrm{kPa}$ somewhat surprisingly, that at high engine speeds the flow becomes "more quasi-steady".

Although one would expect that $Q_{\mathrm{S}}$ should be large (infinite) for steady flows it cannot be used since in that case both $\tau_{\mathrm{g}}$ and $\tau_{\mathrm{c}}$ become infinite and Eq. 13 is not any longer fulfilled.

\subsection{Double-valve experiments}

For steady flow the double-valve experiments give similar results as the single-valve as can be seen from Figs. 21 and 22 although the double valve has a higher dependency on pressure ratio at low valve lifts $(\ell / d \leq 0.086)$. Note that there are only two measurement points in the double valve data for $\ell / d=0.014$, as the rig could not reach a stable condition at higher mass-flow rates.

Dynamic exhaustion experiments for the double-valve setup were performed at an equivalent engine speed of $n=1350 \mathrm{rpm}$. Considering the definition of the $Q_{\mathrm{S}}$ -number (see. Eq. 14): when two valves are used instead of one, the time scale of the geometry is unchanged $\left(2 \dot{A}_{\mathrm{T}} / 2 A_{\mathrm{T}}=\dot{A}_{\mathrm{T}} / A_{\mathrm{T}}\right)$. However, the time scale of the flow

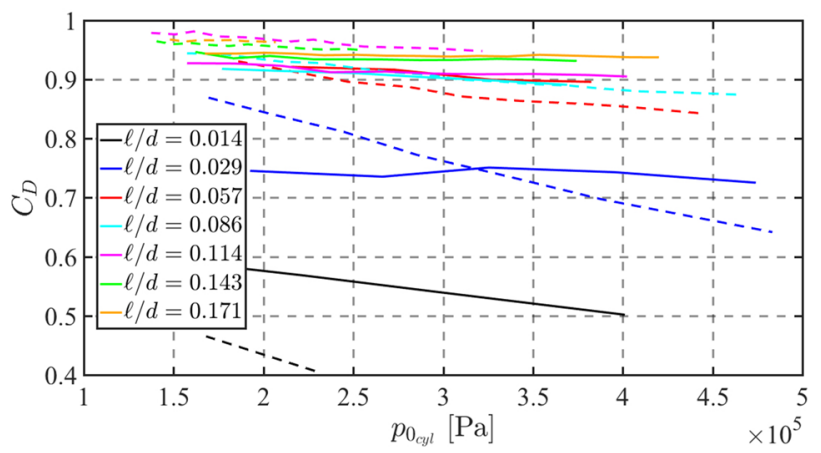

Fig. 21 Static discharge coefficient as a function of cylinder total pressure. Solid lines: single valve experiments. Dashed lines: double valve experiments

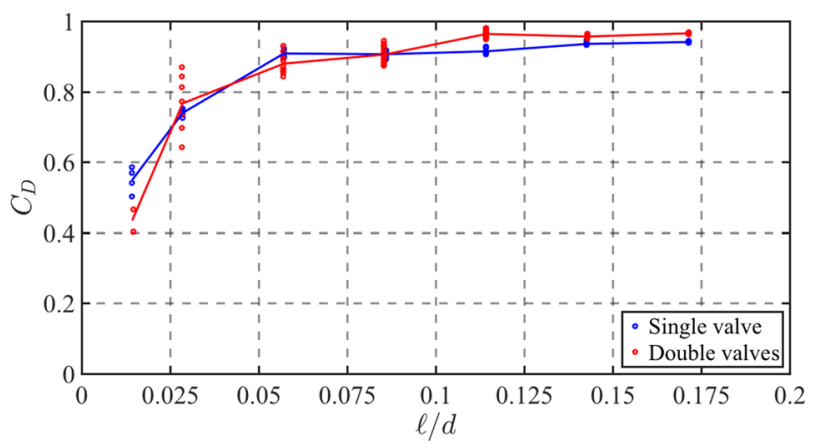

Fig. 22 Static discharge coefficient as a function of valve lift (the solid lines marks the average value of $C_{\mathrm{D}}$ for a given valve lift) 


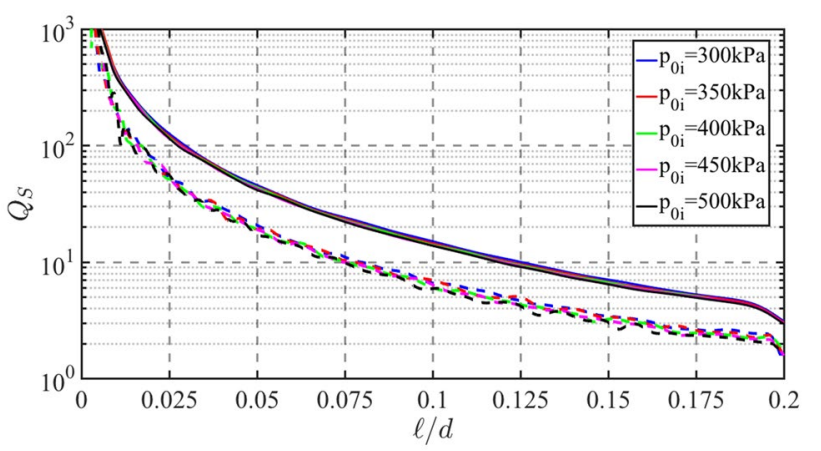

Fig. $23 Q_{\mathrm{S}}$ as a function of valve lift for an equivalent engine speed of 1350 rpm. Solid lines: single-valve experiments. Dashed lines: double-valve experiments

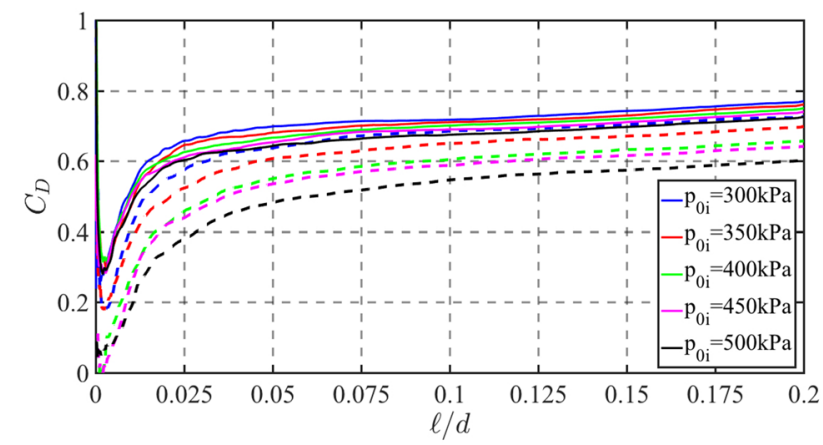

Fig. 24 Dynamic discharge coefficient as a function of valve lift for an equivalent engine speed of $1350 \mathrm{rpm}$. Solid lines: single valve experiments. Dashed lines: double valve experiments

conditions $\left(m_{\mathrm{c}} / \dot{m}\right)$ will be affected, as a larger $A_{\mathrm{T}}$ allows for a larger $\dot{m}$. This means that the cylinder can discharge faster and that the time scale of the flow conditions should decrease, hence reduce the $Q_{\mathrm{S}}$-number relative to the single valve.

The $Q_{\mathrm{S}}$ numbers for the double-valve experiments are plotted as a function of $\ell / d$ in Fig. 23. For comparison the corresponding single valve $Q_{\mathrm{S}}$-numbers are also plotted. The $Q_{\mathrm{S}}$-number drops faster for the double-valve setup, indicating that the quasi-steady assumption is indeed even less valid than for the single-valve setup.

In Fig. $24 C_{\mathrm{D}}$ for both the double (dashed) and single (solid) valve experiments are plotted as a function $\ell / d$. It can be seen that the double-valve setup in general displays a lower $C_{\mathrm{D}}$ than the corresponding singlevalve experiment. The double-valve setup also exhibits a larger dependency on initial pressure than for the single valve. These results support the observation that a more unsteady process has lower $C_{\mathrm{D}}$ and higher pressure ratio dependency.

\section{Summary and conclusions}

An experimental investigation, focussing on the blowdown phase of the exhaust process of an internal combustion engine, has been carried out. The assumptions, i.e. that the flow can be modelled as quasi-steady and that it is pressureratio independent, usually made when using $1 \mathrm{D} / 0 \mathrm{D}$ simulations for engine optimisation, have been examined through a series of experiments. Most of the experiments were done with a single valve, although the effect of a double-valve configuration was also studied. The experiments included evaluating the discharge coefficient $\left(C_{\mathrm{D}}\right)$ under both steady conditions, using a fixed valve, and by emptying a cylinder volume with a dynamically moving valve. The steady flow experiments were made using a high-pressure flow bench, with inlet total pressures up to $500 \mathrm{kPa}$ and mass flow rates up to $0.5 \mathrm{~kg} / \mathrm{s}$. The dynamic estimation of $C_{\mathrm{D}}$ were made by analysing the exhaustion of a pressurised (fixed volume) cylinder. The dynamic setup allowed the initial cylinder pressures and valve opening speeds (equivalent to different engine speeds) to be varied.

Dynamic determination of $C_{\mathrm{D}}$ reveals a dependency on pressure ratio, where an increase in cylinder pressure results in a decrease of $C_{\mathrm{D}}$. This was not anticipated from the static measurements where $C_{\mathrm{D}}$ was rather insensitive to the cylinder pressure. It has also been shown that an increase in engine speed increases the value of $C_{\mathrm{D}}$ as well as decreases the sensitivity to initial cylinder pressure. The dynamic values of $C_{\mathrm{D}}$ are always significantly lower than those for steady flow at equivalent lift. Also the fact that $C_{\mathrm{D}}$ is a function of engine speed suggests that the quasi-steady assumption is not valid.

A measure of the dynamics of the exhaustion process, the quasi-steadiness number $\left(Q_{\mathrm{S}}\right)$, was formulated. This measure relates the time scale of the geometry change to the time scale of the change in flow conditions. The $Q_{\mathrm{S}}$-number has been used to show why the blowdown phase of a typical engine exhaust stroke cannot be considered as quasi-steady. It was observed that as $Q_{\mathrm{S}}$ decreased (indicating a higher level of unsteadiness) the overall value of $C_{\mathrm{D}}$ decreased and the dependency on initial cylinder pressure increased.

As a final conclusion the present experiments show that results of the $C_{\mathrm{D}}$ obtained from static measurements can not be viewed as accurate if implemented in $1 \mathrm{D} / 0 \mathrm{D}$ simulations. When doing simulations one should be aware of this fact and, although rather complicated, strategies for how to use more realistic values of $C_{\mathrm{D}}$, determined from dynamic experiments at relevant pressure ratios, should be pursued. 
Acknowledgements This work was funded by the Competence Center of Gas Exchange (CCGEx) at KTH Royal Institute of Technology, Sweden, a centre supported by the Swedish Energy Agency, Scania CV, Volvo CARS, Volvo Powertrain, Borg Warner and KTH. The workshop staff (Rune Lindfors and Jonas Vikström) of the KTH Fluid Physics Laboratory are gratefully acknowledged for their technical support.

Open Access This article is distributed under the terms of the Creative Commons Attribution 4.0 International License (http://creativecommons.org/licenses/by/4.0/), which permits unrestricted use, distribution, and reproduction in any medium, provided you give appropriate credit to the original author(s) and the source, provide a link to the Creative Commons license, and indicate if changes were made.

\section{References}

Anderson JD (2004) Modern compressible flow: with historical perspective, 3rd edn. McGraw-Hill, New York

Arwatz G, Bahri C, Smits AJ, Hultmark M (2013) Dynamic calibration and modeling of a cold wire for temperature measurement. Meas Sci Technol 24(125):301

Bajsić I, Kutin J, Žagar T (2007) Response time of a pressure measurement system with a connecting tube. Instrum Sci Technol 35:399-409

Benson R (1959) Experiments on two-stroke engine exhaust ports under steady and unsteady flow conditions. Proc Inst Mech Eng 173:511-546

Bohac SV, Landfahrer K (1999) Effects of pulsating flow on exhaust port flow coefficients. SAE Technical Paper 1999-01-0214
Decker J (2013) Critical and steady-flow analysis of a high performance automotive exhaust port. $\mathrm{PhD}$ thesis, University of Miami

Ford CL, Winroth M, Alfredsson PH (2016) Development of a pressure based vortex-shedding meter: measuring unsteady mass-flow in variable density gases. Meas Sci Technol 27:085,901

Heywood JB (1988) Internal combustion engine fundamentals. McGraw-Hill, New York

Laurantzon F, Tillmark N, Örlü R, Alfredsson PH (2012) A flow facility for the characterization of pulsatile flows. Flow Meas Instrum 26:10-17

Povey T, Beard PF (2008) A novel experimental technique for accurate mass flow rate measurement. Flow Meas Instrum 19:251-259

Semlitsch B, Wang Y, Mihăescu M (2014) Flow effects due to pulsation in an internal combustion engine exhaust port. Energ Convers Manag 86:520-536

Semlitsch B, Wang Y, Mihăescu M (2015) Flow effects due to valve and piston motion in an internal combustion engine exhaust port. Energ Convers Manag 96:18-30

Winroth M (2017a) On gas dynamics of exhaust valves. Licentiate thesis, TRITA-MEK 2017:03, Royal Institute of Technology, KTH, Sweden

Winroth PM (2017b) Characterization of and correction for pressuremeasurement installation. Technical report, Royal Institute of Technology, KTH, Sweden

Woods W, Khan S (1965) An experimental study of flow through poppet valves. Proc Inst Mech Eng 180:32-41

Woods W, Khan S (1967) Discharge from a cylinder through a poppet valve to an exhaust pipe. Proc Inst Mech Eng 182:137-144 